Congruent patterns of functional diversity in saproxylic beetles and fungi across European beech forests

\title{
Hagge, Jonas
}

2019-05

Hagge , J , Abrego , N , Baessler , C , Bouget , C , Brin , A , Brustel , H , Christensen , M , Gossner, M M , Heilmann-Clausen , J , Horak , A , Gruppe , A , Isacsson , G , Koehler , F , Lachat, T , Larrieu , L , Schlaghamersky , J , Thorn , S , Zapponi , L \& Mueller , J 2019 , ' Congruent patterns of functional diversity in saproxylic beetles and fungi across European beech forests ' , Journal of Biogeography , vol. 46 , no. 5 , pp. 1054-1065 . https://doi.org/10.1111/jbi.13556

http://hdl.handle.net/10138/310823

https://doi.org/10.1111/jbi.13556

acceptedVersion

Downloaded from Helda, University of Helsinki institutional repository.

This is an electronic reprint of the original article.

This reprint may differ from the original in pagination and typographic detail.

Please cite the original version. 


\title{
Congruent patterns of functional diversity in saproxylic beetles and fungi across European beech forests
}

\author{
Jonas Hagge ${ }^{1,2}$ (D) | Nerea Abrego ${ }^{3}$ (D) | Claus Bässler, ${ }^{2,4}$ | Christophe Bouget ${ }^{5}$ (D) | \\ Antoine Brin $^{6}$ (D) | Herve Brustel ${ }^{6}$ | Morten Christensen ${ }^{7}$ | Martin M.Gossner ${ }^{8}$ | \\ Jacob Heilmann-Clausen ${ }^{9}$ (D) | Jakub Horák ${ }^{10}$ (i) | Axel Gruppe ${ }^{1}$ | Gunnar Isacsson ${ }^{11}$ | \\ Frank Köhler $^{12}$ | Thibault Lachat ${ }^{8,13}$ | Laurent Larrieu ${ }^{14,15}$ (D) | Jiri Schlaghamersky ${ }^{16}$ | \\ Simon Thorn ${ }^{17}$ (D) | Livia Zapponi ${ }^{18}$ | Jörg Müller ${ }^{2,17}$ (D) \\ ${ }^{1}$ Department of Animal Sciences, Chair of Zoology, Entomology Research Group, Technical University of Munich, Freising, Germany \\ ${ }^{2}$ Bavarian Forest National Park, Grafenau, Germany \\ ${ }^{3}$ Department of Agricultural Sciences, University of Helsinki, Helsinki, Finland \\ ${ }^{4}$ Chair of Terrestrial Ecology, Technical University of Munich, Freising, Germany \\ ${ }^{5}$ ‘Forest Ecosystems' Research Unit, National Research Institute of Science and Technology for Environment and Agriculture (Irstea), Nogent-sur-Vernisson, \\ France \\ ${ }^{6}$ Université de Toulouse, Ecole d'Ingénieurs de Purpan, UMR INRA/INPT 1201 Dynafor, Toulouse, France \\ ${ }^{7}$ Hvidtjørnevej 1, Sorø, Denmark \\ ${ }^{8}$ Forest Entomology, Swiss Federal Research Institute WSL, Birmensdorf, Switzerland \\ ${ }^{9}$ Center for Macroecology, Evolution and Climate, Biological Institute, University of Copenhagen, Copenhagen, Denmark \\ ${ }^{10}$ Faculty of Forestry and Wood Sciences, Czech University of Life Sciences Prague, Prague, Czech Republic \\ ${ }^{11}$ Swedish Forest Agency, Hässleholm, Sweden \\ ${ }^{12}$ Strombergstr. 22a, Bornheim, Germany \\ ${ }^{13}$ School of Agricultural, Forest and Food Sciences HAFL, Bern University of Applied Sciences, Zollikofen, Switzerland \\ ${ }^{14}$ UMR 1201 DYNAFOR, INRA, INPT, INPT-EI Purpan, Université de Toulouse, Auzeville Tolosane, France \\ ${ }^{15}$ CRPF-Occitanie, antenne de Tarbes, Tarbes, France \\ ${ }^{16}$ Department of Botany and Zoology, Faculty of Science, Masaryk University, Brno, Czech Republic \\ ${ }^{17}$ Field Station Fabrikschleichach, Department of Animal Ecology and Tropical Biology, Biocenter, University of Würzburg, Rauhenebrach, Germany \\ ${ }^{18}$ Centro Nazionale per lo Studio e la Conservazione della Biodiversità Forestale "Bosco Fontana" Carabinieri, Marmirolo, MN, Italy
}

\section{Correspondence}

Jonas Hagge, Department of Animal Sciences, Chair of Zoology, Entomology Research Group, Technical University of Munich, Freising, Germany.

Email: jonashagge@posteo.de

Editor: Dr. Simone Fattorini

\begin{abstract}
Aim: Beech forests comprise a globally unique temperate forest type in Europe. The dominance of beech in these forests developed during the ongoing post-glacial northward re-colonization, concurrently with intensified forest use by humans. We investigated how these two processes together with climate shaped the patterns of functional diversity of two major species groups involved in wood decomposition and whether functional diversity is determined on the local or regional species pool level. Location: European beech forest distribution range.

Taxon: Saproxylic beetles and fungi.

Methods: We analysed records of 532,496 saproxylic beetles of 788 species and 8,630 records of 234 saproxylic fungal species based on sets of traits similar to both
\end{abstract}


groups. We tested how space, climate and landscape composition affect trait-based functional diversity on local and regional scales. Using structural equation modelling, we tested whether functional diversity is shaped on the local or regional scale.

Results: The response of local functional diversity of both saproxylic beetles and fungi followed a highly congruent pattern of decreasing functional diversity towards the north, with higher elevation and accounted for overall geographical gradients with higher temperature, while increasing with higher precipitation. Structural equation modelling revealed that local functional diversity is determined by community changes operating on the level of the regional species pool.

Main conclusions: Our findings suggest that the functional diversity patterns of saproxylic organisms in European beech forests are mainly determined on the regional scale and driven by anthropogenic and biogeographical processes. To conserve the variation and hotspots of functional diversity in beech forests, activities have to focus on a broad spatial and climatic range of sites throughout Europe, including the primeval forests in the east, as started by the UNESCO World Heritage selection of "Ancient and Primeval Beech Forests of the Carpathians and Other Regions of Europe".

\section{KEYWORDS}

biogeographical history, dead wood, decomposition, Fagus sylvatica, functional diversity, land use intensity, saproxylic beetles, saproxylic fungi

\section{1 | INTRODUCTION}

European beech forests define temperate forests in Central Europe in a globally unique way (Peters, 1997). They are by far the predominant forest association, restricted to Europe and dramatically affected by land use change and intensification (Brunet, Fritz, \& Richnau, 2010). European beech (Fagus sylvatica L.) is separated from Oriental beech (Fagus orientalis Lipsky) by c. 8 Ma (Renner, Grimm, Kapli, \& Denk, 2016). The distribution pattern of European beech is the result of a complex history affected by glaciations and humans. During the last glacial maximum (c. 20,000 years ago), European beech survived in several distinct refugia in southern Europe, but these refugia contributed very differently to the re-colonization process (Magri, 2008), which continues to date, with an expansion of several hundred metres per year towards the north in Sweden (Björkman, 1996) and towards the northeast in Poland (Latalowa, 1992). Early on, natural beech forests began to be replaced by farmland and urban areas, with decreasing historical land use intensity from west to east (Kaplan, Krumhardt, \& Zimmermann, 2009; Peterken, 1996; Rey et al., 2018; Rose, 1992), but distribution was partly also favoured by humans regionally (Björkman, 1997).

The diversity patterns that we observe today in European beech forests evolved under varying paleoclimatic conditions; therefore, the historical climate has shaped the current distribution of biodiversity and ecosystems (Svenning, Eiserhardt, Normand, Ordonez, \& Sandel, 2015). An important determinant of current large-scale biodiversity patterns is the climate of the Quaternary period, with its series of glacial and interglacial phases (Hewitt, 2000). The distance to refugia during cold periods has shaped present species ranges and reduced species richness far from refuges (Hewitt, 1999; Svenning et al., 2010), but might also affect the functional components of biodiversity. For example, the functional diversity of European plants decreases with distance to major glacial temperate refugia and with higher historical climatic instability (Ordonez \& Svenning, 2015). For organisms that depend on the occurrence of long-living species, such as trees, the Quaternary legacy on functional components of biodiversity is more complex. Willner, Di Pietro, and Bergmeier (2009) showed that the distance of European beech to the nearest refugium is the strongest predictor of current lower plant species richness in the understorey of European beech forests. This finding supports the hypothesis that species associated with beech forests are limited by post-glacial dispersal rather than by contemporary environmental factors (Willner et al. 2009).

Nevertheless, species richness at various scales is often strongly influenced by temperature and precipitation (e.g. $\mathrm{H}$ Acevedo \& Currie, 2003). Climatic variables affect distribution, abundance and interaction of species by filtering climate-relevant physiological and behavioural traits (Bellard, Bertelsmeier, Leadley, Thuiller, \& Courchamp, 2012). Due to direct feedback, functional diversity rather than species richness is affected by existing climatic conditions (Bässler et al., 2016; Wright et al., 2005). Finally, land use intensification is a main driver of biodiversity decline in all ecosystems (Kleijn et al., 2009; Mora et al., 2011; Paillet et al., 2010) and is accompanied by multi-trophic homogenization of communities (Gossner et al., 2016). Human resource exploitation can filter species communities by selecting against species 
with particular functional traits (Pauly, Christensen, Dalsgaard, Froese, \& Torres, 1998; Simons, Weisser, \& Gossner, 2016). Thus, functional diversity decline through land use intensification can be steeper than the decline in species richness (Flynn et al., 2009). For example, European saproxylic (i.e. dependent on dead wood) beetles and fungi with large body or fruit body size, respectively, are more affected by forest-use intensification than smaller species (Bässler, Ernst, Cadotte, Heibl, \& Müller, 2014; Seibold et al., 2015).

The environmental filtering effects on assembly processes can operate on different geographical and temporal scales (Kraft et al., 2015). Geographical scales can range from the biome to landscape level to the local habitat down to the microhabitat niche of a species. Jiménez-Alfaro et al. (2018) showed that large-scale environmental and historical factors affected the regional plant species diversity in European beech forests, which in turn, in combination with local habitat conditions, determined species richness of the local plant community. In beech forests, the megadiverse guilds of saproxylic beetles and fungi are the two main agents involved in the important ecosystem process of wood decomposition, which in turn can influence soil biochemistry and therefore forest productivity (Carlyle, 1995; Kappes, Catalano, \& Topp, 2007). Beetles and fungi differ greatly in their biology and life history (Stokland, Siitonen, \& Jonsson, 2012). Fungi directly chemically decompose lignocellulose with secreted enzymes, whereas beetles promote decomposition by mechanical comminution and act as vectors of microorganisms, including fungi (Seibold et al., 2019; Stokland et al., 2012). The community compositions of beetles and fungi and the occurrence of particular decomposer species depend mainly on resource availability, but also on resource heterogeneity, resource connectivity and habitat continuity on different scales, which in turn are influenced by both land use intensity and biogeographical legacies (Bouget
\& Parmain, 2016; Kouki, Hyvärinen, Lappalainen, Martikainen, \& Similä, 2012; Seibold et al., 2016).

To enlarge our current understanding of the main drivers and scales of biodiversity in European beech forests, including space, climate and land use intensity, we assessed the functional diversities of saproxylic beetles and fungi on a regional (forest area) and local (beetle trap catch or fungi log sampling) scale based on the most comprehensive standardized datasets across Europe. To calculate functional diversity, we selected comparable species traits from trait categories that were similar in the two taxa. Owing to the history of European beech after the last glaciation, we expected combined effects of re-colonization history, climatic filters and anthropogenic land use intensity on the functional diversity of saproxylic communities. In particular, we hypothesized a decreasing functional diversity of these communities (a) with distance to the glacial refugia in southwestern, southern and south-eastern Europe, (b) towards dry or cold climates unfavourable for the growth of European beech, and (c) with increasing human land use pressure on regional and European scales. Finally, we tested to which extent these patterns are determined already on the regional species pool level.

\section{2 | MATERIALS AND METHODS}

\subsection{Study area and saproxylic-assemblage data}

We conducted our study on the continental scale across large parts of the distribution range of beech-dominated forests, including different beech forest types ranging from colline to montane zones. We focused on saproxylic species of beetles and fungi. We use the term saproxylic according to the definition of Stokland et al. (2012): "any species that depends, during some part of its life cycle, upon wounded or decaying woody material from living, weakened or
FIGURE 1 Map of Europe showing the study area and sampling locations of saproxylic assemblage data (EPSG 3035; ETRS89 equal area projection). The occurrence of European beech, including natural and naturalized stands, is shown in grey (EUFORGEN), purple dots indicate the sampling locations for saproxylic fungi and yellow dots indicate the sampling locations for saproxylic beetles. Point size refers to the number of samples of local communities sampled within each regional forest area

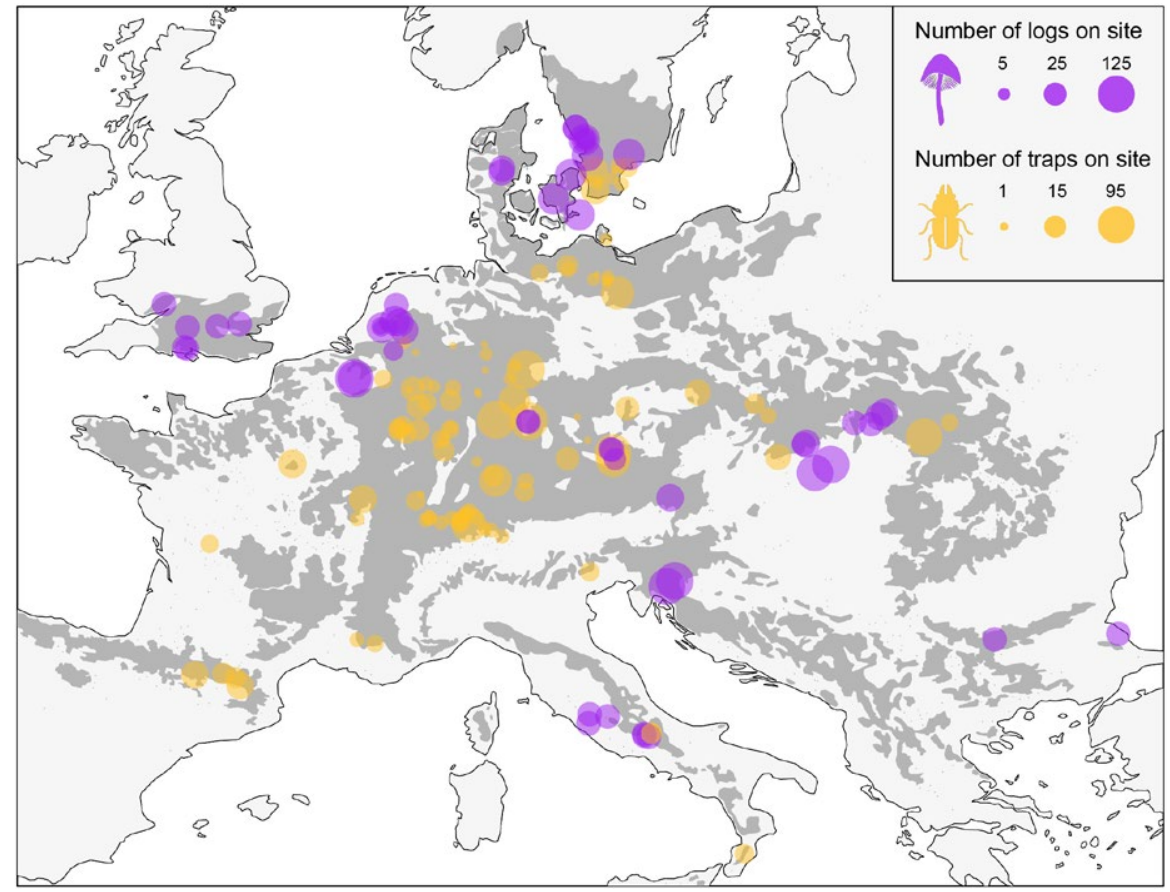


dead trees". For our analyses, we compiled 1,404 flight-interception trap catches of saproxylic beetles covering one full vegetation period nested in 105 beech-dominated managed and protected forest areas from 10 countries, and we sampled saproxylic fungi in fruiting body surveys of 1,814 fallen beech logs nested in 53 different beech-dominated forest areas from 12 countries (Figure 1). We defined a region as the forest area sampled by the sum of the traps or logs within a district forest site, and the regional species pool as the total species present within the traps or logs of one forest area. Local communities represented all species sampled per trap or log. For further information on the sampling of saproxylic beetles and fungi, see Appendix S1. The sampling procedures for beetles (mobile taxon) with passive continuously collecting traps, and for fungi (sessile taxon) with active object-oriented sampling differed. Also the sampling localities of the two taxa differed broadly (Figure 1). Two taxonomical and geographical independent datasets represent two replications to understand assembly processes in European beech forests.

\subsection{Environmental data}

We described the three dimensions of space using latitudinal and longitudinal coordinates (based on the ETRS 1989 projection) and elevation (metres above sea level). We used latitude as a measure of distance of beech forest areas to glacial refugia in southern Europe (Magri, 2008). We are aware that other proxies for distance of postglacial dispersal routes, e.g. proximity to refugia, can be used (e.g. Jiménez-Alfaro et al., 2018). However, proximity to refugia based on a climatic suitability model of European beech in the last glacial maximum can be applied with different potential paleoclimatic scenarios and still neglects effects of landscape topography during re-colonization. Thus, these proxies based on further assumptions also result in high uncertainty (cf. Lehsten et al., 2014). Elevation of beech forest areas is related to the biogeographical history because European beech started re-colonization of Europe after glaciation at higher elevations before extending to lower elevations (Magri, 2008). We used longitude as a proxy for the decreasing historical land use intensity in European beech forests from west to east (Peterken, 1996; Rose, 1992).

In addition to space, we used landscape characteristics and climate as environmental predictors. We used information from the pan-European project CORINE Land Cover (www.corine.dfd.dlr. de) to calculate the following landscape characteristics: proportion of human settlement as a measure of small-scale land use intensity, proportion of forest, and proportion of broad-leaved forest compared to the forest area within a 3-km radius (for details, see Gossner et al., 2013; Müller et al., 2015). We extracted and used the local climatic variables mean temperature of the warmest quarter (BIO10) and precipitation of the warmest quarter (BIO18) from WorldClim (Hijmans, Cameron, Parra, Jones, \& Jarvis, 2005) grid data in $30 \mathrm{~s}$ resolution and calculated mean values for a $1-\mathrm{km}$ radius around sampled localities, following the methodology of Gossner et al. (2013) and Müller et al. (2015). We calculated all environmental variables for each local community (i.e. position of trap or log) and for each regional community (i.e. forest area) as the mean of all traps or logs in the forest area. To test for collinearity of climate and landscape predictor variables, we calculated the variance inflation factor using the 'vif' function in the add-on package usDM (Naimi, Hamm, Groen, Skidmore, \& Toxopeus, 2013); the results indicated that none of the local climate and landscape predictor variables had collinearity problems (all values of vif $<1.9$ ). A problem in many large-scale studies is that latitude correlates with declining temperature (e.g. Deutsch et al., 2008; Zeuss, Brandl, Brändle, Rahbek, \& Brunzel, 2014), which may complicate the interpretation of a biogeographical history effect (latitude as a gradient of biogeographical history) and the effects of current climate (latitude as a proxy for temperature). However, this correlation does not impact the distribution range of European beech forests and was not a factor in our environmental datasets of beetles and fungi (Appendix S3) because the distribution and thus the climatic niche of European beech is at a higher elevation in the southern range of these trees (e.g. Pyrenees, Apennines, Balkans) and at a lower elevation in their northern range (e.g. Northern Germany, Denmark, Southern Sweden; Peters, 1997) of European beech forests.

\section{3 | Functional traits}

Despite the generally different lifestyles of saproxylic beetles and fungi, we gathered a set of functional traits of both taxa that reflect comparable trait categories. In relation to the traits selected in Seibold et al. (2015), we selected biological and resource-related traits available for both saproxylic groups (Table 1). Body size, decay niche, wood diameter niche and host tree preference were traits we could collect for both groups. Organismal body size is a highly integrative trait representing, for example, metabolic rate, dispersal ability and demographical properties (LaBarbera, 1989). Resourcerelated traits define the dimensions of the species niche within dead wood as a complex habitat varying in space and time in its physical and chemical properties (Stokland et al., 2012). For the calculation of resource-related traits, we followed the procedure of Gossner et al. (2013) and determined the occurrence of species in ordered classes: decay niche, alive, freshly dead, initiated, advanced decomposition, extremely decomposed; wood diameter niche, <15, 15-35, 35-70, $>70 \mathrm{~cm}$; canopy niche, open, semi-open, closed. The frequency of occurrence of each species in each category was then described by weighting scores based on the calculated mean niche position (for details, see Appendix S2 and Gossner et al., 2013). Note that the host tree association of a species reflects the preference of that species and is not an exclusive category. We tested for collinearity of traits separately for saproxylic beetles and fungi using the 'vif' function in the add-on package USDM (Naimi et al., 2013); the results indicated that none of the traits chosen had collinearity problems (all values of vif $<1.7$; for a correlation matrix plot, see Appendix S2). Trait data were gathered from primary literature and other publications and were also determined by authors with expertise and by external experts. Data on the traits of saproxylic beetles and fungi, 


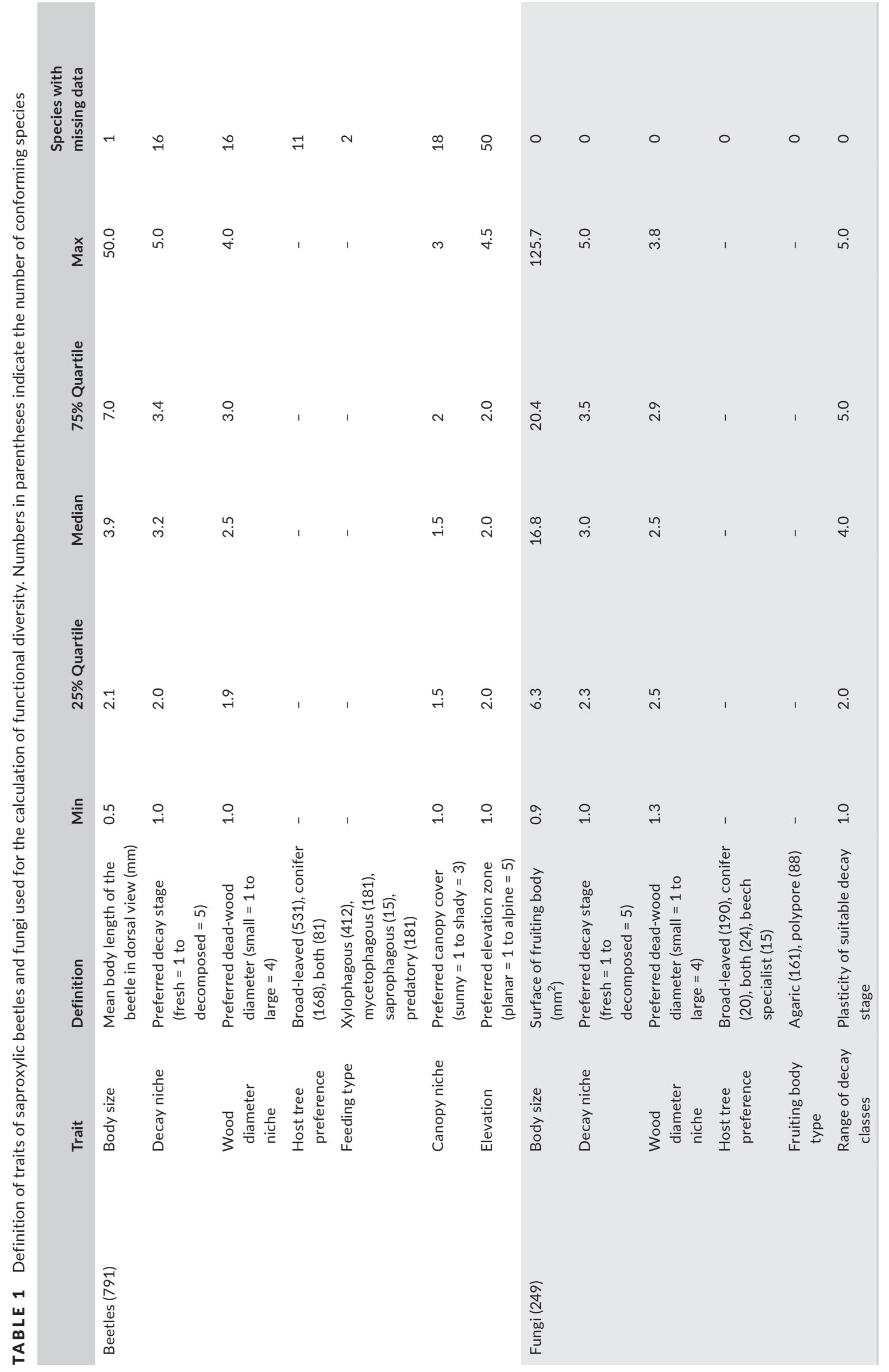


detailed references, and methods of trait sampling are presented in Appendix S2.

\subsection{Statistical analyses}

All analyses were performed in R version 3.3.3 (R Core Team, 2015). We used a measure of functional diversity describing divergence, i.e. how similar are the species within an assemblage (Cadotte \& Davis, 2016). Functional diversity was calculated as the mean pairwise distance (MPD) between functional traits in the functional space of cooccurring species (Mouillot, Graham, Villéger, Mason, \& Bellwood, 2012; Webb, Ackerly, Mcpeek, \& Donoghue, 2002). To control for variations in the number of species in the different assemblages and to obtain a metric for the assembly patterns, we applied a null-model approach to our final functional diversity, using the tip-shuffling method (Cadotte \& Davis, 2016). This provided standardized effects sizes of the mean pairwise distances (SES MPD), which we calculated with 999 randomizations using the function 'ses.mpd' in the addon package PICANTE (Kembel et al., 2010). Functional diversity based on species-by-species distance matrices was calculated using the Gower distance (Gower, 1971) of the presence-absence datasets of saproxylic beetles and fungi, using the 'gowdis' function in the addon package FD (Laliberte \& Legendre, 2010). The dissimilarity coefficient of Gower (1971) can simultaneously combine continuous and categorical traits. Functional diversity was calculated for each local and regional community of beetles and fungi.

We first tested our predictions separately for local and regional functional diversity. For local functional diversity, we applied linear mixed-effects models with our set of environment predictor variables representing space, climate and landscape (Table 2), separately for beetles and fungi. To control for replicated measurements within the same forest area, forest area was treated as a random term. For regional functional diversity, we applied linear models with our set of environment predictor variables representing space, climate and landscape (Table 2), separately for beetles and fungi. Secondly, to test direct and indirect effects of the predictors at the regional and local community levels, we used structural equation modelling (Shipley, 2016) and added regional functional diversity as a predictor to the model of local functional diversity. We used the function 'sem.coefs' in the add-on package PIECEWISESEM (Lefcheck, 2016), which allows the creation of lists of models with random effects to control for nested measurements and accounts for data distribution (Shipley, 2016). Single-path coefficients were scaled by mean and variance to make single-variable importance comparable.

\section{3 | RESULTS}

Our final dataset for beetles included 105 forest areas for regional functional diversity and 1,401 traps for local functional diversity. The final dataset for fungi included 53 forest areas for regional functional diversity and 1,618 logs for local functional diversity. These datasets comprised 532,496 records of 788 saproxylic beetle species and 8,630 records of 234 saproxylic fungus species. The functional diversity of saproxylic beetles and fungi indicated the clumping of traits at both local (beetles: $-1.52 \pm 1.26$ [mean SES \pm SD], Appendix

TAB LE 2 Environmental predictor variables used for evaluation of functional diversity of saproxylic assemblages in European beech forests. Measurement units and the covered range of variables for the assemblage data of saproxylic beetles and fungi are given

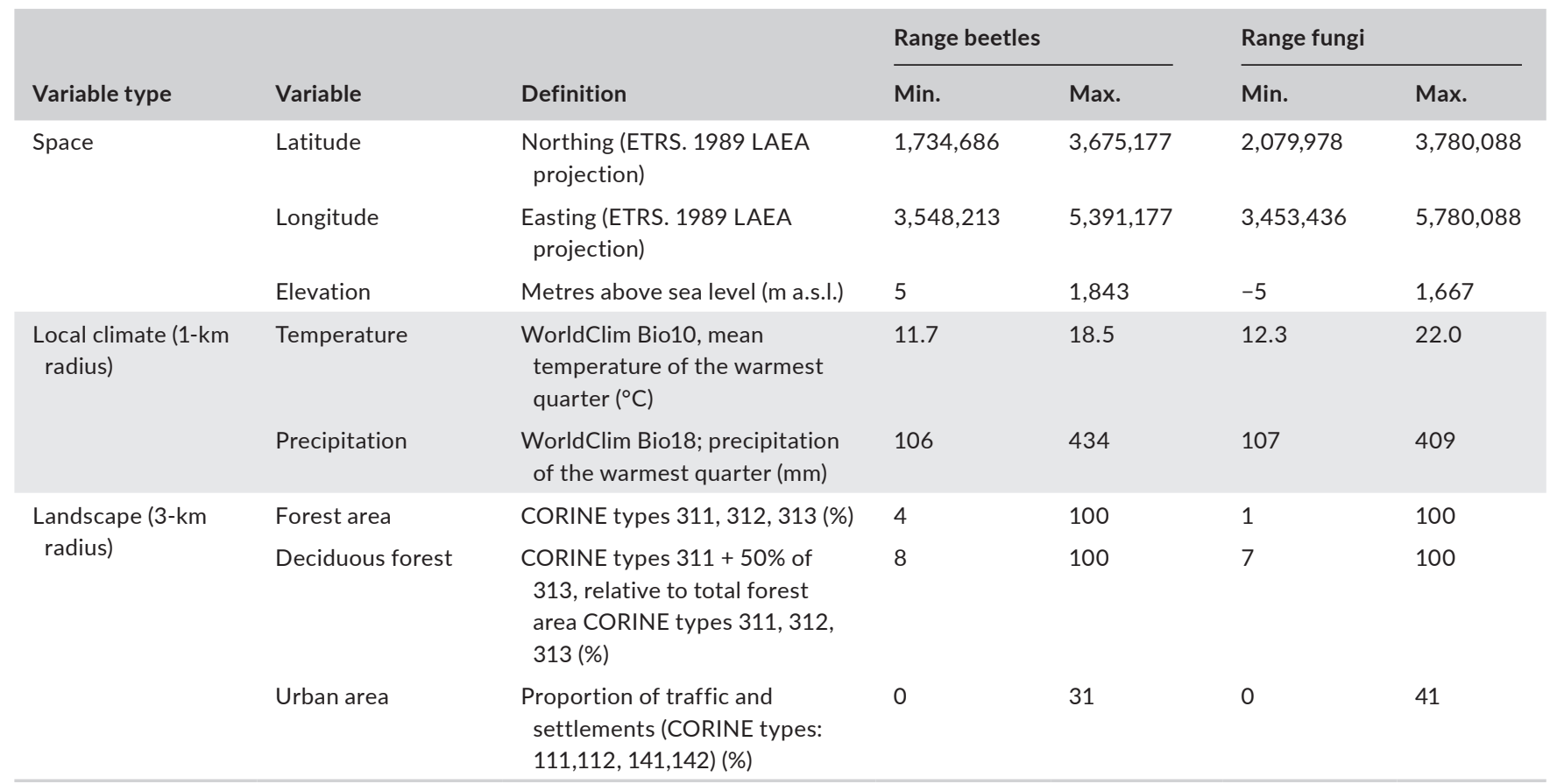

ERTS: European Terrestrial Reference System; LAEA: Lambert azimuthal equal-area projection; CORINE: Pan-European project CORINE Land Cover (CLC) (CORINE 2006). 


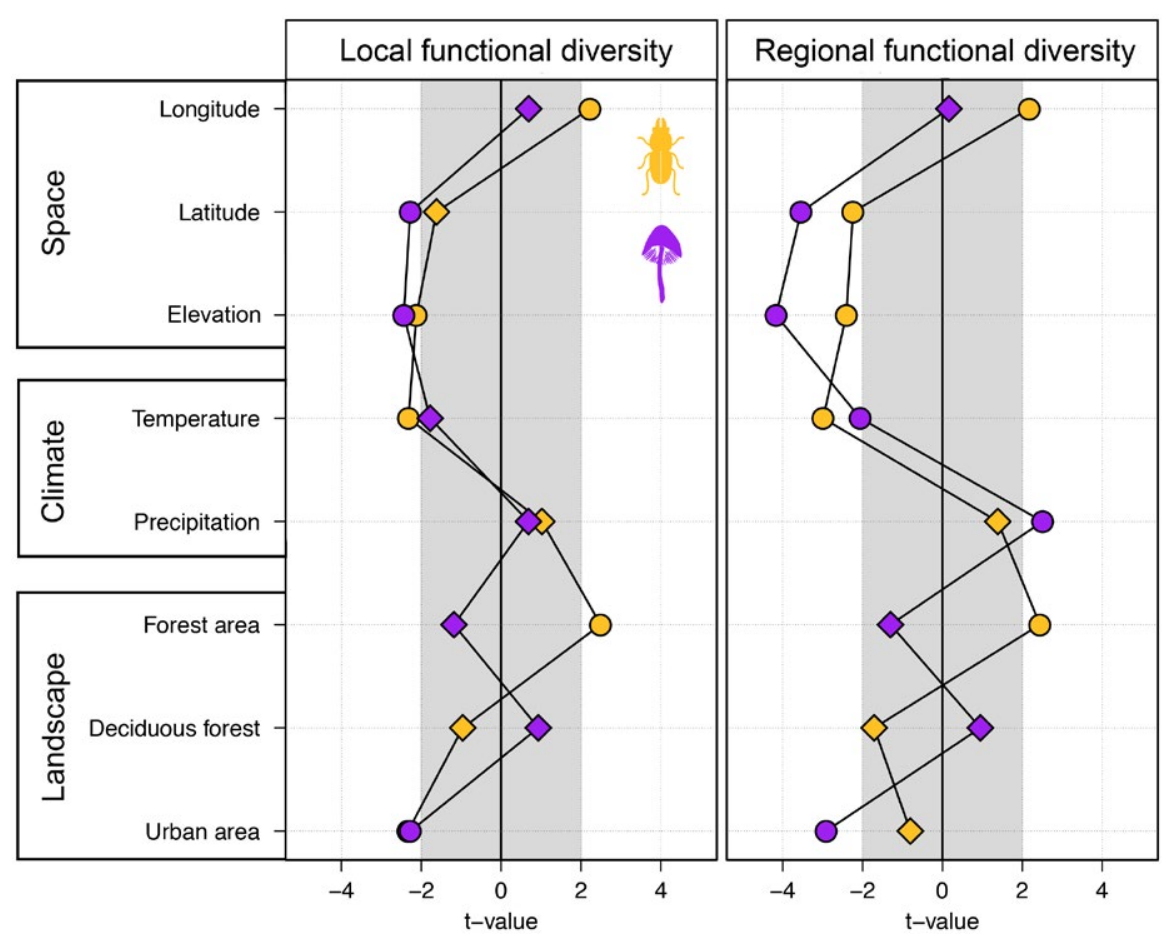
regional functional diversity (standardized effect sizes of the mean pairwise distances) of saproxylic beetles (yellow) and fungi (purple) to predictor variables representing space, climate and landscape in European beech forests. Circles indicate significant effects $(p<0.05)$ and diamonds indicate non-significant effects (lines between points are for visual purposes only); shaded areas indicate ranges of non-significant values ( $t$-values: \pm 2.0 )
FIGURE 2 Response of local and

MPDs of species traits within communities) of beetles and fungi were similar (Appendix S5). $-2.90 \pm 1.17$, Appendix S4: Figure S4.9) scales. Thus, both the species within local assemblages and the regional species pools were more similar in their trait characteristics than would occur by chance (considering the random composition of European fungus and beetle communities).

The response of functional diversity of saproxylic beetles to environmental variables on the local and regional scales followed the same patterns as that of saproxylic fungi (Figure 2; Appendix S4: Table S4.3). However, the structural equation model indicated that environmental filtering of functional diversity by space, climate and landscape composition operated mainly on the regional scale, which was congruent for saproxylic beetles and fungi (Figure 3; Appendix S4: Table S4.4). Functional diversity of saproxylic beetles and fungi congruently decreased towards northern Europe (Figures 2 and 3; Appendix S4). Moreover, the functional diversity of both groups decreased with increasing elevation and temperature (Figures 2 and 3; Appendix S4). With higher precipitation, functional diversity of saproxylic beetles and fungi congruently increased (Figures 2 and 3; Appendix S4). The regional functional diversity of beetles was higher in eastern Europe than in the west, and the proportion of urban areas in the landscape had a negative effect on local functional diversity (Figures 2 and 3; Appendix S4). The proportion of urban areas in the landscape also negatively affected fungal functional diversity but operated on the regional scale (Figures 2 and 3; Appendix S4). The results regarding the functional diversity of saproxylic beetles were robust when conifer-associated beetle species were excluded from the analyses (Appendix S4: Figure S4.10). Results of models with raw values of functional diversity (observed

\section{4 | DISCUSSION}

Our independent datasets of saproxylic beetles and saproxylic fungi yielded congruent response patterns of functional diversity to space and climatic and landscape variables across the biogeographical range of European beech forests. Most of these patterns were already determined on the scale of the regional species pool. In line with our expectation, functional diversity of saproxylic organisms decreased along a historical re-colonization gradient of European biota from south to north. A suitable climate regime for European beech consistently promoted the functional diversity of associated saproxylic taxa of beetles and fungi. Furthermore, we found a negative effect of the proportion of urban areas in the landscape on functional diversity and also a negative effect of land use intensity along the east-west continental gradient; the latter was significant only for beetles.

\subsection{Functional clumping of decomposers across Europe}

Over the biogeographical range of European beech, functional diversities of the associated saproxylic taxa showed clumping, which could be explained mainly on the regional species pool level. This suggests that local and regional saproxylic communities were functionally less diverse than could be expected based on a random sample of the species in our study. We consider this trend to be general, 


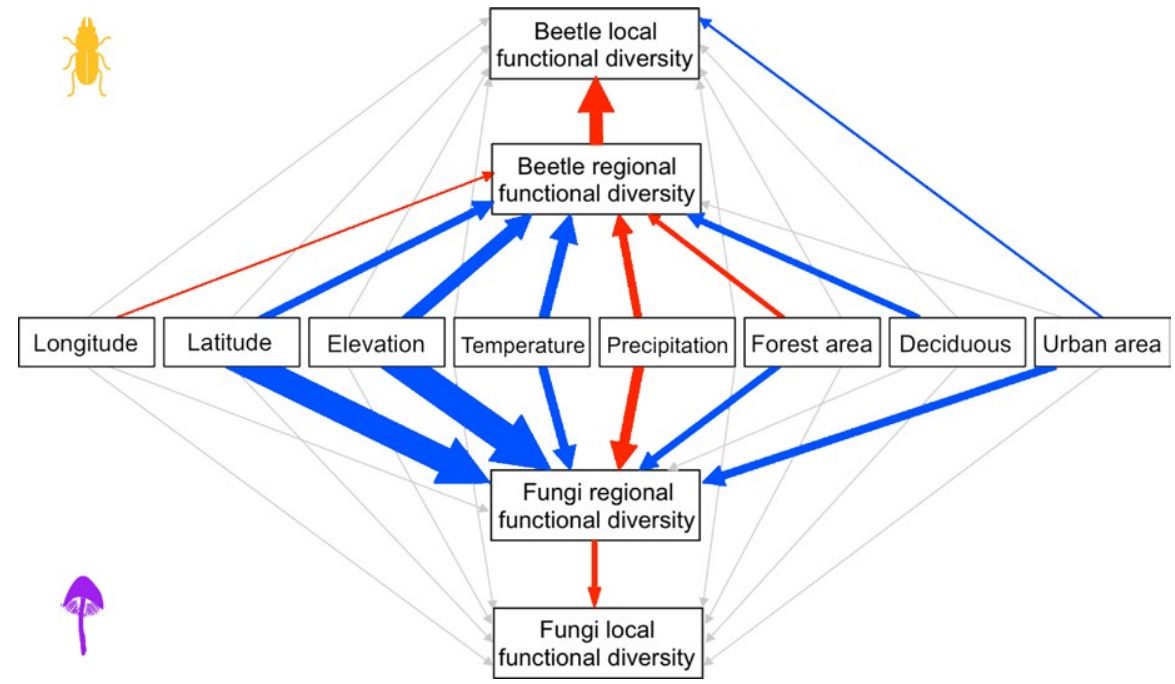

FIGURE 3 Structural equation models indicating relationships between predictor variables representing space, climate and landscape and regional and local functional diversity of saproxylic beetles (top) and fungi (bottom). The scale of path coefficients of positive (red) and negative (blue) relationships correspond to arrow width. All test paths are shown; non-significant ones are in grey

as c. $90 \%$ of the species of saproxylic taxa that can be expected based on our sampling protocols (i.e. gamma diversity; sample coverage of $99.7 \%$, see Appendix S6) were covered by our study throughout the entire biogeographical range of European beech forests. Therefore, saproxylic communities comprised species with more similar morphological traits, in particular ecological niche requirements, than could have been expected from a random community composition across European beech forests. The consistent filtering effects on the functional diversities of saproxylic beetles and fungi across Europe in the present study might thus be driven by biogeographical history, climate and gradients of land use intensity, which we discuss in the following paragraphs.

\section{2 | Gradient of biogeographical history}

Many studies investigating latitude consider the south-north gradient as a gradient of declining temperature (e.g. Deutsch et al., 2008; Zeuss et al., 2014). However, this is not the case in European beech forests, where in the north the temperature decline is counteracted by an elevation decline covering the distribution range of European beech forests (Appendix S3). Thus, in European beech forest latitude represents a gradient of biogeographical history made pronounced by palaeoclimatic oscillations between cold and warm periods (Hewitt, 2000; see Section 2 for different proxies of biogeographical history). We measured within the latitudinal range of European beech forests a decrease in functional diversity towards the north. More specifically, functional traits were more clustered in the north than in the south. This indicates that the dominant assembly pattern of decomposers shifts from a more random ecological drift in the south to habitat filtering in the north. The underlying process might be explained by the ongoing post-glacial northward expansion of beech forest (Magri, 2008). In other words, community composition and structure in the northern range of European beech forests might not yet have reached equilibrium with the environment. For obligate forest-associated taxa, such as saproxylic organisms, dispersal and adaptation to new suitable regions could even be concomitant with longer temporal lags (Yang et al., 2010). Conversely, lower functional diversity in the north could be caused not only by local habitat filtering, but also by facilitation of re-colonization of saproxylic species, with specific functional traits leading to functional clustering in correlation with distance to refugia during cold periods. This has been found to be the case for plant species across Europe, where the ratio of realized-to-potential functional richness and dispersion are highest in areas with low climatic instability and close to the major glacial refugia (Ordonez \& Svenning, 2015).

\subsection{Climatic filter on functional diversity}

European beech forests have their ecological optimum under Atlantic climatic conditions, which are more pronounced in the west and less pronounced in the east, where climatic conditions become increasingly continental until European beech reaches its eastern distribution limit (Peters, 1997). In contrast with the positive effect of increasing temperature for taxonomic diversity of saproxylic beetles (Müller et al., 2015) and saproxylic fungi (Abrego, Bässler, Christensen, \& Heilmann-Clausen, 2015) in European beech forests, we found a negative effect of increasing temperature for functional diversity of both species groups when we accounted for overall geographical gradients (latitude and elevation). Saproxylic communities in European beech forests with higher temperatures are functionally less diverse than those in forests with lower temperatures. This is a functional filter that already operates on the regional scale of different forests, with the local scale simply being a blueprint thereof. In this case, we assumed a stronger environmental filtering of functional traits under higher temperature regimes, often related to desiccation stress. In global and regional diversity analyses, it has 
also been shown that different facets of diversity do not obligatorily match and that taxonomic and functional diversities can differ in response to climatic filters (Bae et al., 2018; Bässler et al., 2016; Stuart-Smith et al., 2013). Thus, for diversity conservation, multiple facets of biodiversity should be considered and approaches that integrate diversity facts for prioritization and incorporate the complementarity of site selection should be promoted (see Cadotte and Tucker 2018 for a recent new concept involving a holistic approach). Precipitation, another regional climatic filter of the functional diversity of saproxylic beetles and fungi in European beech forests, also had a significant effect, with generally higher functional diversity in moister climates. We therefore hypothesized that higher precipitation in beech forests favours tree species, such as Norway spruce (Picea abies (L.) H. Karst.) and silver fir (Abies alba Mill.), that promote the functional diversity of saproxylic species. In general, we conclude that a higher functional diversity of saproxylic communities can be found in regions with climatic conditions favouring European beech growth, namely sufficient precipitation and a moderate temperature regime (Peters, 1997).

\subsection{Negative effect of land use intensity on functional diversity}

Negative effects of land use intensity can cause effects on the landscape scale or arise as a result of extensive land use intensity on the continental and global scales (Brunet et al., 2010; Foley et al., 2005; Strona et al., 2016). We found a negative effect of land use intensity on functional diversity of saproxylic beetles and fungi in European beech forests on the landscape scale (i.e. proportion of urban area within a $3-\mathrm{km}$ radius). Higher land use intensity thus strengthened the effect of habitat filtering on species assemblages, which results in lower functional diversity and ultimately in functional homogenization, as shown for taxonomic diversity (Gossner et al., 2016). The functional diversity decrement observed in our study lends support to the idea that species loss is not a random process and affects some species more strongly than others because of particular functional traits, as shown by a modelling approach of extinction risk of saproxylic beetles (Seibold et al., 2015). Saproxylic beetles of lowlands, large species and species that rely on wood of large diameter, broad-leaved trees, or open canopy had a higher extinction risk, which well reflects forestry intensification in European forests in the last centuries (Seibold et al., 2015). On the continental scale, only saproxylic beetles had functionally more diverse communities in eastern Europe than in the west, which follows human land use history in Europe (Peterken, 1996; Rose, 1992) and the more ancient beech forests in the east (e.g. Carpathians).

\subsection{Functional diversity and the regional species pool}

We found a clear pattern of biogeographical history, climate and landscape composition operating as filters of functional diversity on the regional species pool level; local functional diversity just represented a blueprint. This assembly process was the same for saproxylic beetles and fungi. Therefore, the functional trait space of species in a local habitat or even on a particular substrate in the case of fungi was determined by the regional species pool of forest areas and not predominantly by local habitat characteristics. These findings perfectly match the beta-diversity patterns of saproxylic beetles in European beech forests, with highest species turnover between different forest areas (Müller et al., 2012). They also support findings on the dispersal of saproxylic fungi and beetles on larger scales (Komonen \& Müller, 2018). Jiménez-Alfaro et al. (2018) also showed that biogeographical and climatic factors filter plant species richness in European beech forest on the regional species pool level and that only small operative habitat conditions further alter local species diversity. Although the lifestyles of saproxylic beetles and saproxylic fungi highly differ, a functional filter dominated on the regional pool of both groups.

\subsection{Implications for the conservation of biodiversity in European beech forests}

Due to the high variety of European beech forest habitats, these forests harbour about $70 \%$ of the saproxylic beetles in Central Europe (Müller et al., 2012). Local taxonomic diversity and especially threatened species in European beech forests are promoted by high amounts of dead wood, high numbers of veteran trees, high dead-wood diversity, high diversity of tree-related microhabitats and long habitat continuity (Bouget, Larrieu, Nusillard, \& Parmain, 2013; Brunet et al., 2010; Ódor et al., 2006; Paillet et al., 2010; Seibold et al., 2016; Stokland et al., 2012). Our results add new evidence that the functional diversities of saproxylic beetles and fungi in European beech forests were congruently filtered by biogeographical history, climate and human land use intensity and that beech forests mainly differ on a landscape scale in their functional space of saproxylic organisms. These congruent results for saproxylic beetles and fungi provide an opportunity to protect areas with high functional diversity simultaneously for these two hyperdiverse taxa in the decomposition of wood. However, protecting a few beech forest sites is not sufficient to protect the range of functional diversity in European beech forests. Instead, a comprehensive network of protected areas representing the geographical and climate range of European beech forests is necessary to protect the entire functional range of biodiversity. Thus, conservationists and politicians have to reinforce their efforts to promote and expand suitable European-wide conservation strategies, such as the Natura 2000 network with 13 different European beech forest habitat types, including four priority habitat types and the UNESCO World Heritage of "Ancient and Primeval Beech Forests of the Carpathians and Other Regions of Europe". This is all the more urgent because, in the face of climate change, it has been predicted that areas of high functional diversity in European beech forest in southern and eastern Europe will be most affected by climate warming (Jones, Murphy, \& Noguer, 1995; Seneviratne, Lüthi, Litschi, \& Schär, 2006). A double hit by climate change and the 
reduction in buffering structures, such as dead wood, by management (Müller et al., 2015) might push beech ecosystems out of their resilience range (Seidl, Spies, Peterson, Stephens, \& Hicke, 2016).

\section{ACKNOWLEDGEMENTS}

We thank Andrej Piltaver, Mirjam Veerkamp, Ruben Walleyn and Iren Siller for providing part of the fungal data, Torsten Hothorn for statistical advice, Karen A. Brune and Wendy Ran for linguistic revision of the manuscript.

\section{DATA ACCESSIBILITY}

Trait data of 791 saproxylic beetle species and 249 saproxylic fungus species (Appendix S2) are provided with this article. Some of the data pertain to endangered species and are therefore classified; to protect these species, data on their occurrence cannot be made available to the general public.

\section{ORCID}

Jonas Hagge (iD https://orcid.org/0000-0001-8938-6680

Nerea Abrego (iD https://orcid.org/0000-0001-6347-6127

Christophe Bouget iD https://orcid.org/0000-0002-5206-7560

Antoine Brin iD https://orcid.org/0000-0003-3479-3005

Martin M. Gossner (iD https://orcid.org/0000-0003-1516-6364

Jacob Heilmann-Clausen iD https://orcid.org/0000-0003-4713-6004

Jakub Horák (iD https://orcid.org/0000-0003-2049-0599

Laurent Larrieu iD https://orcid.org/0000-0002-9050-0281

Simon Thorn (iD https://orcid.org/0000-0002-3062-3060

Jörg Müller iD https://orcid.org/0000-0002-1409-1586

\section{REFERENCES}

Abrego, N., Bässler, C., Christensen, M., \& Heilmann-Clausen, J. (2015). Implications of reserve size and forest connectivity for the conservation of wood-inhabiting fungi in Europe. Biological Conservation, 191, 469-477. https://doi.org/10.1016/j.biocon.2015.07.005

Bae, S., Müller, J., Lee, D., Vierling, K. T., Vogeler, J. C., Vierling, L. A., ... Thorn, S. (2018). Taxonomic, functional, and phylogenetic diversity of bird assemblages are oppositely associated to productivity and heterogeneity in temperate forests. Remote Sensing of Environment, 215, 145-156. https://doi.org/10.1016/j. rse.2018.05.031

Bässler, C., Cadotte, M. W., Beudert, B., Heibl, C., Blaschke, M., Bradtka, J. H., ... Müller, J. (2016). Contrasting patterns of lichen functional diversity and species richness across an elevation gradient. Ecography, 39, 689-698. https://doi.org/10.1111/ecog.01789

Bässler, C., Ernst, R., Cadotte, M., Heibl, C., \& Müller, J. (2014). Near-tonature logging influences fungal community assembly processes in a temperate forest. Journal of Applied Ecology, 51, 939-948. https://doi. org/10.1111/1365-2664.12267

Bellard, C., Bertelsmeier, C., Leadley, P., Thuiller, W., \& Courchamp, F. (2012). Impacts of climate change on the future of biodiversity. Ecology Letters, 15, 365-377. https://doi. org/10.1111/j.1461-0248.2011.01736.x

Björkman, L. (1996). The late Holocene history of beech Fagus sylvatica and Norway spruce Picea abies at stand-scale in southern Sweden. LUNDQUA Thesis, 1-44.

Björkman, L. (1997). The role of human disturbance in the local Late Holocene establishment of Fagus and Picea forests at Flahult, western Smhland, southern Sweden. Vegetation History and Archaeobotany, 6, 79-90. https://doi.org/10.1007/BF01261956

Bouget, C., Larrieu, L., Nusillard, B., \& Parmain, G. (2013). In search of the best local habitat drivers for saproxylic beetle diversity in temperate deciduous forests. Biodiversity and Conservation, 22, 2111-2130. https://doi.org/10.1007/s10531-013-0531-3

Bouget, C., \& Parmain, G. (2016). Effects of landscape design of forest reserves on saproxylic beetle diversity. Conservation Biology, 30, $92-$ 102. https://doi.org/10.1111/cobi.12572

Brunet, J., Fritz, Ö., \& Richnau, G. (2010). Biodiversity in European beech forests - a review with recommendations for sustainable forest management. Ecological Bulletins, 53, 77-94.

Cadotte, M. W., \& Davis, T. J. (2016). Phylogenies in ecology: A guide to concepts and methods. Princeton, NJ: Princeton University Press.

Cadotte, M. W., \& Tucker, C. M. (2018). Difficult decisions: Strategies for conservation prioritization when taxonomic, phylogenetic and functional diversity are not spatially congruent. Biological Conservation, 225, 128-133. https://doi.org/10.1016/j.biocon.2018.06.014

Carlyle, J. C. (1995). Nutrient management in Pinus radiata plantation after thinning: The effect of thinning and residues on nutrient distribution, mineral nitrogen fluxes, and extractable phosphorus. Canadian Journal of Forest Research, 25, 1278-1291. https://doi. org/10.1139/x95-141

Deutsch, C. A., Tewksbury, J. J., Huey, R. B., Sheldon, K. S., Ghalambor, C. K., Haak, D. C., \& Martin, P. R. (2008). Impacts of climate warming on terrestrial ectotherms across latitude. Proceedings of National Academy of Sciences of the United States of America, 105, 6668-6672. https://doi.org/10.1073/pnas.0709472105

Flynn, D. F. B., Gogol-Prokurat, M., Nogeire, T., Molinari, N., Richers, B. T., Lin, B. B., ... DeClerck, F. (2009). Loss of functional diversity under land use intensification across multiple taxa. Ecology Letters, 12, 2233. https://doi.org/10.1111/j.1461-0248.2008.01255.x

Foley, J. A., DeFries, R., Asner, G. P., Barford, C., Bonan, G., Carpenter, S. R., ... Snyder, P. K. (2005). Global consequences of land use. Science, 209, 570-575. https://doi.org/10.1126/science.1111772

Gossner, M. M., Lachat, T., Brunet, J., Isacsson, G., Bouget, C., Brustel, H., ... Müller, J. (2013). Current near-to-nature forest management effects on functional trait composition of saproxylic beetles in beech forests. Conservation Biology, 27, 605-614. https://doi.org/10.1111/ cobi.12023

Gossner, M. M., Lewinsohn, T. M., Kahl, T., Grassein, F., Boch, S., Prati, D., ... Allan, E. (2016). Land-use intensification causes multitrophic homogenization of grassland communities. Nature, 540, 266-269. https://doi.org/10.1038/nature20575

Gower, J. C. (1971). A general coefficient of similarity and some of its properties. Biometrics, 27, 857-871. https://doi.org/10.2307/2528823

H-Acevedo, D. \& Currie, D. J. (2003). Does climate determine broadscale patterns of species richness? A test of the causal link by natural experiment. Global Ecology and Biogeography, 12, 461-473. https:// doi.org/10.1046/j.1466-822X.2003.00058.x

Hewitt, G. (1999). Post-glacial re-colonization of European biota. Biological Journal of the Linnean Society, 68, 87-112. https://doi. org/10.1111/j.1095-8312.1999.tb01160.x

Hewitt, G. (2000). The genetic legacy of the Quaternary ice ages. Nature, 405, 907-913. https://doi.org/10.1038/35016000

Hijmans, R. J., Cameron, S. E., Parra, J. L., Jones, P. G., \& Jarvis, A. (2005). Very high resolution interpolated climate surfaces for global land 
areas. International Journal of Climatology, 25, 1965-1978. https://doi. org/10.1002/(ISSN)1097-0088

Jiménez-Alfaro, B., Girardello, M., Chytrý, M., Svenning, J. C., Willner, W., Gégout, J. C., ... Wohlgemuth, T. (2018). History and environment shape species pools and community diversity in European beech forests. Nature Ecology and Evolution, 2, 483-490. https://doi. org/10.1038/s41559-017-0462-6

Jones, R. G., Murphy, J. M., \& Noguer, M. (1995). Simulation of climate change over Europe using a nested regional-climate model. I: Assessment of control climate, including sensitivity to location of lateral boundaries. Quarterly Journal of the Royal Meteorological Society, $121,1413-1449$.

Kaplan, J. O., Krumhardt, K. M., \& Zimmermann, N. (2009). The prehistoric and preindustrial deforestation of Europe. Quaternary Science Reviews, 28, 3016-3034. https://doi.org/10.1016/j. quascirev.2009.09.028

Kappes, H., Catalano, C., \& Topp, W. (2007). Coarse woody debris ameliorates chemical and biotic soil parameters of acidified broad-leaved forests. Applied Soil Ecology, 36, 190-198. https://doi.org/10.1016/j. apsoil.2007.02.003

Kembel, S. W., Cowan, P. D., Helmus, M. R., Cornwell, W. K., Morlon, H., Ackerly, D. D., ... Webb, C. O. (2010). Picante: R tools for integrating phylogenies and ecology. Bioinformatics, 26, 1463-1464. https://doi. org/10.1093/bioinformatics/btq166

Kleijn, D., Kohler, F., Báldi, A., Batáry, P., Concepción, E. D., Clough, Y., ... Verhulst, J. (2009). On the relationship between farmland biodiversity and land-use intensity in Europe. Proceedings of the Royal Society B: Biological Sciences, 276, 903-909. https://doi.org/10.1098/ rspb.2008.1509

Komonen, A., \& Müller, J. (2018). Dispersal ecology of dead wood organisms: Implications for connectivity conservation. Conservation Biology, 32, 535-545. https://doi.org/10.1111/cobi.13087

Kouki, J., Hyvärinen, E., Lappalainen, H., Martikainen, P., \& Similä, M. (2012). Landscape context affects the success of habitat restoration: Large-scale colonization patterns of saproxylic and fire-associated species in boreal forests. Diversity and Distributions, 18, 348-355. https://doi.org/10.1111/j.1472-4642.2011.00839.x

Kraft, N. J. B., Adler, P. B., Godoy, O., James, E. C., Fuller, S., \& Levine, J. M. (2015). Community assembly, coexistence and the environmental filtering metaphor. Functional Ecology, 29, 592-599. https://doi. org/10.1111/1365-2435.12345

LaBarbera, M. (1989). Analyzing body size as a factor in ecology and evolution. Annual Review of Ecology and Systematics, 20, 97-117. https:// doi.org/10.1146/annurev.es.20.110189.000525

Laliberte, E., \& Legendre, P. (2010). A distance-based framework for measuring functional diversity from multiple traits. Ecology, 91, 299305. https://doi.org/10.1890/08-2244.1

Latalowa, M. (1992). Man and vegetation in the pollen diagrams from Wolin Island (NW Poland). Acta Palaeobotanica, 32, 123-249.

Lefcheck, J. S. (2016). piecewiseSEM: Piecewise structural equation modelling in R for ecology, evolution, and systematics. Methods in Ecology and Evolution, 7, 573-579. https://doi.org/10.1111/2041-210X. 12512

Lehsten, D., Dullinger, S., Hülber, K., Schurgers, G., Cheddadi, R., Laborde, H., ... Sykes, M. T. (2014). Modelling the Holocene migrational dynamics of Fagus sylvatica L. and Picea abies (L.) H. Karst. Global Ecology and Biogeography, 23, 658-668. https://doi.org/10.1111/geb. 12145

Magri, D. (2008). Patterns of post-glacial spread and the extent of glacial refugia of European beech (Fagus sylvatica). Journal of Biogeography, 35, 450-463. https://doi.org/10.1111/j.1365-2699.2007.01803.x

Mora, C., Aburto-Oropeza, O., Bocos, A. A., Ayotte, P. M., Banks, S., Bauman, A. G., ... Zapata, F. A. (2011). Global human footprint on the linkage between biodiversity and ecosystem functioning in reef fishes. PLoS Biology, 9, e1000606.
Mouillot, D., Graham, N. A. J., Villéger, S., Mason, N. W. H., \& Bellwood, D. R. (2012). A functional approach reveals community responses to disturbances. Trends in Ecology and Evolution, 28, 167-177.

Müller, J., Brunet, J., Brin, A., Bouget, C., Brustel, H., Bussler, H., ... Gossner, M. M. (2012). Implications from large-scale spatial diversity patterns of saproxylic beetles for the conservation of European Beech forests. Insect Conservation and Diversity, 6, 162-169.

Müller, J., Brustel, H., Brin, A., Bussler, H., Bouget, C., Obermaier, E., ... Gossner, M. M. (2015). Increasing temperature may compensate for lower amounts of dead wood in driving richness of saproxylic beetles. Ecography, 38, 499-509. https://doi.org/10.1111/ecog.00908

Naimi, B., Hamm, N. A. S., Groen, T. A., Skidmore, A. K., \& Toxopeus, A. G. (2013). Where is positional uncertainty a problem for species distribution modelling? Ecography, 37, 191-203.

Ódor, P., Heilmann-Clausen, J., Christensen, M., Aude, E., van Dort, K. W., Piltaver, A., ... Grebenc, T. (2006). Diversity of dead wood inhabiting fungi and bryophytes in semi-natural beech forests in Europe. Biological Conservation, 131, 58-71.

Ordonez, A., \& Svenning, J.-C. (2015). Geographic patterns in functional diversity deficits are linked to glacial-interglacial climate stability and accessibility. Global Ecology and Biogeography, 24, 826-837. https:// doi.org/10.1111/geb.12324

Paillet, Y., Bergès, L., Hjältén, J., Ódor, P., Avon, C., BernhardtRömermann, M., ... Virtanen, R. (2010). Biodiversity differences between managed and unmanaged forests: Meta-analysis of species richness in Europe. Conservation Biology, 24, 101-112. https://doi. org/10.1111/j.1523-1739.2009.01399.x

Pauly, D., Christensen, V., Dalsgaard, J., Froese, R., \& Torres, F. Jr (1998). Fishing down marine food webs. Science, 279, 860-863. https://doi. org/10.1126/science. 279.5352 .860

Peterken, G. F. (1996). Natural woodland: Ecology and conservation in northern temperate regions. Cambridge, UK: Cambridge University Press.

Peters, R. (1997). Beech forests. Dordrecht, The Netherlands: Springer. https://doi.org/10.1007/978-94-015-8794-5

R Core Team. (2015). R: A language and environment for statistical computing. Vienna, Austria: R Foundation for Statistical Computing.

Renner, S. S., Grimm, G. W., Kapli, P., \& Denk, T. (2016). Species relationships and divergence times in beeches: New insights from the inclusion of 53 young and old fossils in a birth - Death clock model. Philosophical Transactions of the Royal Society B, 271, 20150135. https://doi.org/10.1098/rstb.2015.0135

Rey, F., Gobet, E., Schwörer, C., Wey, O., Hafner, A., \& Tinner, W. (2018). Causes and mechanisms of synchronous succession trajectories in primeval Central European mixed Fagus sylvatica forests. Journal of Ecology, in press.

Rose, F. (1992). Temperate forest management, its effect on bryophyte and lichen floras and habitats. In J. W. Bates \& A. M. Farmer (Eds.), Bryophytes and Lichens in a changing environment (pp. 223-245). Oxford, UK: Clarendon Press.

Seibold, S., Bässler, C., Brandl, R., Büche, B., Szallies, A., Thorn, S., ... Müller, J. (2016). Microclimate and habitat heterogeneity as the major drivers of beetle diversity in dead wood. Journal of Applied Ecology, 53, 934-943. https://doi.org/10.1111/1365-2664.12607

Seibold, S., Brandl, R., Buse, J., Hothorn, T., Schmidl, J., Thorn, S., \& Müller, J. (2015). Association of extinction risk of saproxylic beetles with ecological degradation of forests in Europe. Conservation Biology, 29, 382-390. https://doi.org/10.1111/cobi.12427

Seibold, S., Müller, J., Krah, F-S., Baldrian, P., Cadotte, M. W., Brandl, R., ... Bässler, C. (2019). Fungi associated with beetles dispersing from dead wood - Let's take the beetle bus! Fungal Ecology, 39, 100-108. https:// doi.org/10.1016/j.funeco.2018.11.016

Seidl, R., Spies, T. A., Peterson, D. L., Stephens, S. L., \& Hicke, J. A. (2016). Searching for resilience: Addressing the impacts of changing disturbance regimes on forest ecosystem services. Journal of Applied Ecology, 53, 120-129. https://doi.org/10.1111/1365-2664.12511 
Seneviratne, S. I., Lüthi, D., Litschi, M., \& Schär, C. (2006). Landatmosphere coupling and climate change in Europe. Nature, 443, 205-209. https://doi.org/10.1038/nature05095

Shipley, B. (2016). Cause and correlation in biology (2nd ed.). Cambridge, UK: Cambridge University Press. https://doi.org/10.1017/ CBO9781139979573

Simons, N. K., Weisser, W. W., \& Gossner, M. M. (2016). Multi-taxa approach shows consistent shifts in arthropod functional traits along grassland land-use intensity gradient. Ecology, 97, 754-764.

Stokland, J. N., Siitonen, J., \& Jonsson, B. G. (2012). Biodiversity in dead wood. Cambridge, UK: Cambridge University Press. https://doi. org/10.1017/CВO9781139025843

Strona, G., Mauri, A., Veech, J. A., Seufert, G., Ayanz, J. S.-M., \& Fattorini, S. (2016). Far from naturalness: How much does spatial ecological structure of European tree assemblages depart from potential natural vegetation? PLoS ONE, 11, e0165178. https://doi.org/10.1371/ journal.pone. 0165178

Stuart-Smith, R. D., Bates, A. E., Lefcheck, J. S., Duffy, J. E., Baker, S. C., Thomson, R. J., ... Edgar, G. J. (2013). Integrating abundance and functional traits reveals new global hotspots of fish diversity. Nature, 501, 539-542. https://doi.org/10.1038/nature12529

Svenning, J., Eiserhardt, W. L., Normand, S., Ordonez, A., \& Sandel, B. (2015). The Influence of paleoclimate on present-day patterns in biodiversity and ecosystems. Annual Review of Ecology, Evolution, and Systematics, 46, 551-572. https://doi.org/10.1146/ annurev-ecolsys-112414-054314

Svenning, J.-C., Fitzpatrick, M. C., Normand, S., Graham, C. H., Pearman, P. B., Iverson, L. R., \& Skov, F. (2010). Geography, topography, and history affect realized-to-potential tree species richness patterns in Europe. Ecography, 33, 1070-1080. https://doi. org/10.1111/j.1600-0587.2010.06301.x

Webb, C. O., Ackerly, D. D., Mcpeek, M. A., \& Donoghue, M. J. (2002). Phylogenies and community ecology. Annual Review of Ecology and Systematics, 33, 475-505. https://doi.org/10.1146/annurev. ecolsys.33.010802.150448

Willner, W., Di Pietro, R., \& Bergmeier, E. (2009). Phytogeographical evidence for post-glacial dispersal limitation of European beech forest species. Ecography, 32, 1011-1018. https://doi. org/10.1111/j.1600-0587.2009.05957.x
Wright, I. J., Reich, P. B., Cornelissen, J. H. C., Falster, D. S., Groom, P. K., Hikosaka, K.,...Westoby, M. (2005). Modulation of leaf economic traits and trait relationships by climate. Global Ecology and Biogeography, 14, 411-421. https://doi.org/10.1111/j.1466-822x.2005.00172.x

Yang, L. H., Edwards, K. F., Byrnes, J. E., Bastow, J. L., Wright, A. N., \& Spence, K. O. (2010). A meta-analysis of resource pulse - consumer interactions. Ecological Monographs, 80, 125-151. https://doi. org/10.1890/08-1996.1

Zeuss, D., Brandl, R., Brändle, M., Rahbek, C., \& Brunzel, S. (2014). Global warming favours light-coloured insects in Europe. Nature Communications, 5, 3874. https://doi.org/10.1038/ncomms4874

\section{BIOSKETCH}

The Beech boys were initially a group of fungus specialists who sampled saproxylic fungi in European beech forests. This group recently joined a group of saproxylic beetle specialists to become a European-wide community of dead-wood ecologists. Deadwood ecology is a growing discipline with the potential of contributing to a broad field of general biological questions.

\section{SUPPORTING INFORMATION}

Additional supporting information may be found online in the Supporting Information section at the end of the article.

How to cite this article: Hagge J, Abrego N, Bässler C, et al. Congruent patterns of functional diversity in saproxylic beetles and fungi across European beech forests. J Biogeogr. 2019;00:1-12. https://doi.org/10.1111/jbi.13556 